\title{
Radiculopathy in degenerative lumbar scoliosis: treatment with selective nerve root steroid injections
} Avraam Ploumis*1,2, Ensor E Transfeldt ${ }^{1}$, Thomas J Gilbert ${ }^{3}$,
Amir A Mehbod $^{1}$, Manuel R Pinto ${ }^{1}$, Jill W Wroblewski ${ }^{1}$ and Francis Denis ${ }^{1}$

\author{
Address: ${ }^{1}$ Twin Cities Spine Center, Minneapolis, Minnesota, USA, 225 Mitropoleos St., Thessaloniki 54624, Greece and ${ }^{3}$ Center for Diagnostic \\ Imaging, Saint Louis Park, Minnesota, USA \\ Email: Avraam Ploumis* - ploumis@med.auth.gr \\ * Corresponding author
}

from 4th International Conference on Conservative Management of Spinal Deformities

Boston, MA, USA. 13-16 May 2007

Published: 12 October 2007

Scoliosis 2007, 2(Suppl I):S38 doi:10.1186/1748-7|6I-2-SI-S38

This abstract is available from: http://www.scoliosisjournal.com/content/2/SI/S38

(C) 2007 Ploumis et al; licensee BioMed Central Ltd.

\section{Objective}

To define the origin of radiculopathy of patients with degenerative lumbar scoliosis and to assess the correlation between percentage of radiculating pain relief with selective nerve root injections and lateral canal dimensions.

\section{Methods}

Ninety-three consecutive patients (average age sixty-eight years) with degenerative de novo scoliosis (74\% lumbar, $26 \%$ thoracolumbar; average curve 24 degrees) were retrospectively studied in terms of presenting symptomatology. For those patients with ipsilateral radicular symptoms, plain radiographs and MRI at presentation were reviewed. Radiographic measurements included major and lumbosacral curve Cobb angle. Computerized measurements of MRI included minimum subarticular height and foramen cross-sectional area of the nerve root that was injected. The patient's reported response from the nerve root injections was rated poor, good and excellent $(<50 \%, 50-70 \%,>70 \%$ of relief). Correlation between MRI measurements and response from the steroid injections were done with the Pearson's test.

\section{Results}

Eighty-one percent of the patients presented with back pain, $61 \%$ with radicular symptoms, $15 \%$ with imbalance and $40 \%$ with neurogenic claudication. Based on the results from the selective nerve root injections and from the fifty patients with radicular symptoms, $36 \%$ had nerve root symptoms coming from the major curve, $60 \%$ from the lumbosacral hemicurve and $4 \%$ from both. The affected nerve roots were more frequently the L4 (26\%) and L5 nerve roots. Seventy-five percent of the cases had radicular symptoms coming from the concavity of the curve, $15 \%$ from the convexity and $20 \%$ from both sides. In the cases with ipsilateral radicular symptomatology (n $=41$ ), there was no statistical significant correlation ( $\mathrm{p}>$ 0.05 ) between the lateral canal dimensions and the response.

\section{Conclusion}

In degenerative scoliotic curves, radicular symptoms come mainly from the concavity of the lumbosacral hemicurve. There is no evidence that the rate of relief from selective nerve root injections correlates with the degree of stenosis noted in the MRI. 